\title{
PENGARUH MOBILISASI DINI TERHADAP NYERI POST OPERASI SECTIO CESSAREA DI RUMAH SAKIT BENGKULU
}

\author{
Des Metasari ${ }^{1}$, Berlian Kando Sianipar ${ }^{2}$ \\ Program studi DIII Keperawatan Universitas Dehasen Bengkulu \\ desmetasari@unived.ac.id
}

\begin{abstract}
ABSTRAK
Menurut Word Health Organization (WHO) memperkirakan pada tahun 2008 dilaporkan bahwa wanita melahirkan dengan SC sebanyak 35\% dari seluruh persalinan, sedangkan di Indonesia berdasarkan hasil Riskesdas 2010 menyatakan terdapat $15,3 \%$ persalinan dilakukan melalui operasi. Provinsi tertinggi dengan persalinan melalui SC adalah DKI Jakarta (27,2\%), Kepulauan Riau (24,7\%), dan Sumatera Barat (23,1\%). Tujuan penelitian ini adalah untuk menganalisis persepsi ibu tentang nyeri post operasi section caesarea (SC), bahwa mobilisasi atau pergerakan itu tidak akan meningkatkan nyeri, justru sebaliknya pergerakan dapat menurun kan intensitas nyeri. Rancangan penelitian menggunakan metode pre eksperimental dengan pendekatan one group pretest-post test. Sampel dalam penelitian ini berjumlah 40 orang ibu post operasi section caesarea di Rumah Sakit se kota Bengkulu dengan tehnik sampling menggunakan accidental sampling. Hasil penelitian menunjukkan bahwa terdapat pengaruh mobilisasi dini dengan penurunan intensitas nyeri post operasi SC dengan nilai $P$ value 0,000 . Kesimpulan penelitian ini adalah mobilisasi dini dapat menurunkan intensitas nyeri pasien post operasi SC sehingga disarankan kepada pihak Rumah Sakit Agar melaksanakan mobilisasi dini kepada pasien post op sectio caesarea.
\end{abstract}

Kata Kunci : Mobilisasi dini, post operasi, nyeri

\section{PENDAHULUAN}

Tindakan Sectio cassarea (SC) merupakan salah satu alternatif bagi seorang wanita dalam memilih proses persalinan di samping adanya indikasi medis dan indikasi non medis, tindakan SC akan memutuskan kontinuitas atau persambungan jaringan karena insisi yang akan mengeluarkan reseptor nyeri sehingga pasien akan merasakan nyeri terutama setelah efek anastesi habis. ${ }^{1}$ Rasa nyeri dapat menimbulkan stressor dimana individu berespon secara biologis dimana hal ini dapat menimbulkan respon perilaku fisik dan psikologis. ${ }^{5}$

Mobilisasi dini adalah upaya untuk memandirikan pasien secara bertahap mengingat besarnya tanggung jawab yang harus dilakukan oleh ibu untuk pemulihannya dan merawat bayinya, namun banyak ibu takut melakukan pergerakan karena takut merasa nyeri padahal pergerakan itu dapat mengurangi nyeri selain itu mobilisasi dini dapat melatih kemandirian ibu. ${ }^{7}$ Mobilisasi dini merupakan faktor yang menonjol dalam mempercepat pemulihan pasca bedah dan dapat mencegah komplikasi pasca bedah, dengan mobilisasi dini diharapkan ibu nifas dapat menjadi lebih sehat dan lebih kuat, selain itu juga dapat melancarkan pengeluaran lochea, membantu proses penyembuhan luka akibat proses persalinan, mempercepat involusio uteri, melancarkan fungsi alat gastro intestinal dan alat perkemihan serta meningkatkan kelancaran peredaran darah, sehingga mempercepat pengeluaran Air Susu Ibu (ASI) dan pengeluaran sisa metabolisme. ${ }^{9}$

Menurut Word Health Organitation (WHO) memperkirakan pada tahun 2008 dilaporkan bahwa wanita melahirkan dengan SC sebanyak 35\% dari seluruh persalinan, sedangkan di Indonesia berdasarkan hasil Riskesdas 2010 menyatakan terdapat 15,3\% persalinan dilakukan melalui operasi. Provinsi tertinggi dengan persalinan melalui SC adalah DKI Jakarta (27,2\%), Kepulauan Riau (24,7\%), dan Sumatera Barat (23,1\%). ${ }^{3}$

Berdasarkan data Rekam Medik dari rumah sakit Bengkulu pada tahun 2013 jumlah ibu yang melakukan SC berjumlah 905 orang, tahun 2014 jumlah ibu yang melakukan SC meningkat menjadi 1086, tahun 2015 
berjumlah 1010 dan tahun 2016 priode Januari s/d 172 orang ibu yang melakukan SC. Hal ini menunjukkan bahwa Tindakan Sectio caesarea setiap tahunnya mengalami peningkatan.

Penelitian ini bertujuan untuk pengaruh mobilisasi dini pasien post operasi SC dengan penururnan intensitas nyeri pasien post operasi SC. ${ }^{3}$

\section{METODE}

Jenis penelitian yang digunakan adalah desain penelitian eksperimen semu (Quasy experiment). Karena peneliti tidak mengontrol semua variabel yang relevan, dengan pendekatan One Group Pre-Post Test yang bertujuan untuk melihat pengaruh mobilisasi dini terhadap intensitas nyeri pada pasien post op sectio cessarea. Populasi dalam penelitian ini adalah seluruh ibu yang post operasi sectio caessarea dalam 6 jam pertama dengan sampel dalam penelitian ini adalah sebagian dari populasi pasien post operasi sectio cassarea berjumlah 40 orang yang diambil dengan teknik accidental sampling, sedangkan alat yang digunakan untuk mengukur skala nyeri menggunakan Numeric Rating Scale (NRS). Pengukuran nyeri dilakukan pada menit ke 60 dengan tiga kali intervensi mobilisasi dini masing-masing 15 menit untuk setiap kali intervensi. Penelitian ini dilakukan, tempat penelitian di Rumah sakit se kota Bengkulu dari bulan Agustus s/d September 2017.

\section{HASIL}

\section{Analisis Univariat}

Hasil penelitian menunjukkan bahwa hampir sebagian responden mengalami tingkat nyeri 5 dan 6 berjumlah 14 (35,0\%) dan hampir sebagian responden mengalami tingkat nyeri 3 berjumlah $18(45,0 \%)$.

\section{Analisis Bivariat}

Berdasarkan tabel diatas hasil penelitian menunjukkan rata-rata penurunan tingkat nyeri adalah 2,2 dan terdapat pengaruh mobilisasi dini terhadap penurunan intensitas nyeri dimana nilai $p \leq 0,05$ dan nilai $p(0,000)$.

Tabel 1.

Frekuensi Tingkat Nyeri Sebelum Dilakukan Mobilisasi Dini Pada Pasien

Post Op Sectio Caesarea di Rumah Sakit Se Kota Bengkulu

\begin{tabular}{ccc}
\hline Tingkat Nyeri & Frekuensi & Persentase (\%) \\
\hline 4 & 5 & 12.5 \\
\hline 5 & 14 & 35.0 \\
\hline 6 & 14 & 35.0 \\
\hline 7 & 7 & 17.5 \\
\hline Total & $\mathbf{4 0}$ & $\mathbf{1 0 0}$ \\
\hline
\end{tabular}

Sumber: Data Penelitian, 2017 
Tabel 2.

Frekuensi Tingkat Nyeri Sesudah Dilakukan Mobilisasi Dini Pada Pasien Post Op Sectio Caesarea di Rumah Sakit Se Kota Bengkulu

\begin{tabular}{ccc}
\hline Tingkat Nyeri & Frekuensi & Persentase (\%) \\
\hline 1 & 1 & 2.5 \\
\hline 2 & 4 & 10.0 \\
\hline 3 & 18 & 45.0 \\
\hline 4 & 14 & 35.0 \\
\hline 5 & 3 & 7.5 \\
\hline Total & $\mathbf{4 0}$ & $\mathbf{1 0 0}$ \\
\hline
\end{tabular}

Tabel 3.

Pengaruh Mobilisasi Dini Terhadap Intensitas Nyeri Pada Pasien Post Op Sectio Caesarea di Rumah Sakit Se Kota Bengkulu

\begin{tabular}{|c|c|c|c|c|c|c|c|c|}
\hline & \multicolumn{5}{|c|}{ Paired Differences } & \multirow[b]{3}{*}{$\mathbf{T}$} & \multirow[b]{3}{*}{ Df } & \multirow{3}{*}{$\begin{array}{l}\text { Sig. (2- } \\
\text { tailed) }\end{array}$} \\
\hline & \multirow[b]{2}{*}{ Mean } & \multirow{2}{*}{$\begin{array}{c}\text { Std. } \\
\text { Deviation }\end{array}$} & \multirow{2}{*}{$\begin{array}{c}\text { Std. Error } \\
\text { Mean }\end{array}$} & \multicolumn{2}{|c|}{$\begin{array}{c}\text { 95\% Confidence } \\
\text { Interval of the } \\
\text { Difference }\end{array}$} & & & \\
\hline & & & & Lower & Upper & & & \\
\hline $\begin{array}{c}\text { Tingkat Nyeri } \\
\text { Sebelum Mobilisasi } \\
\text { TingkatNyeri } \\
\text { Sesudah Mobilisasi }\end{array}$ & 2.2250 & 65974 & 10431 & 2.01401 & 2.43599 & 21.330 & 39 & .000 \\
\hline
\end{tabular}

\section{PEMBAHASAN}

Mobilisasi dini adalah upaya untuk memandirikan pasien secara bertahap mengingat besarnya tanggung jawab yang harus dilakukan oleh ibu untuk pemulihannya dan merawat bayinya, namun banyak ibu takut melakukan pergerakan karena takut merasa nyeri padahal pergerakan itu dapat mengurangi nyeri selain itu mobilisasi dini dapat melatih kemandirian ibu.

Ibu yang melakukan mobilisasi dini akan mempercepat proses penyembuhan pasca melahirkan, selain itu gerakan lebih awal yang dilakukan ibu dapat menghindari terjadinya infeksi pada bekas luka sayatan setelah operasi sectio cessarea, mengurangi resiko terjadinya konstipasi mengurangi terjadinya dekubitus, kekakuan atau penegangan otot - otot di seluruh tubuh, mengatasi terjadinya gangguan sirkulasi darah, pernafasan, peristaltik maupun berkemih. Mobilisasi dini merupakan faktor yang menonjol dalam mempercepat pemulihan pasca bedah dan dapat mencegah komplikasi pasca bedah, dengan mobilisasi dini diharapkan ibu nifas dapat menjadi lebih sehat dan lebih kuat, selain itu juga dapat melancarkan pengeluaran lochea, membantu proses penyembuhan luka akibat proses persalinan, mempercepat involusio uteri, melancarkan fungsi alat gastro intestinal dan alat perkemihan serta meningkatkan kelancaran peredaran darah, sehingga mempercepat pengeluaran Air Susu Ibu (ASI) dan pengeluaran sisa metabolisme.

Hasil penelitian ini sesuai dengan penelitian yang sudah dilakukan oleh oleh Dewi et al., tahun 2014 yang membuktikan ada hubungan faktor nyeri dengan pelaksanaan mobilisasi dini, nyeri dapat menurun dengan pergerakan ibu post operasi SC yang dilakukan secara bertahap dan sedini mungkin. ${ }^{2}$ 
Kerugian jika tidak dilakukan mobilisasi dini peningkatan suhu tubuh karena adanya involusi uterus yang tidak baik sehingga sisa darah tidak dapat dikeluarkan dan menyebabkan infeksi dan salah satu dari gejala infeksi adalah peningkatan suhu tubuh; perdarahan yang abnormal, dengan mobilisasi dini kontraksi uterus akan baik sehingga fundus uteri keras, maka resiko perdarahan yang abnormal dapat dihindarkan, karena kontraksi membentuk penyempitan pembuluh darah yang terbuka; involusi uterus yang tidak baik, tidak dilakukan mobilisasi secara dini akan menghambat pengeluaran darah dan sisa plasenta sehingga menyebabkan terganggunya kontraksi uterus.

Rasa nyeri dapat menimbulkan stressor dimana individu berespon secara biologis, hal ini dapat menimbulkan respon perilaku fisik dan psikologis. Mobilisasi dini adalah upaya untuk memandirikan pasien secara bertahap mengingat besarnya tanggung jawab yang harus dilakukan oleh ibu untuk pemulihannya dan merawat bayinya, namun banyak ibu takut melakukan pergerakan karena takut merasa nyeri padahal pergerakan itu dapat mengurangi nyeri selain itu mobilisasi dini dapat melatih kemandirian ibu.

\section{KESIMPULAN DAN SARAN}

Mobilisasi dini sangat efektif bagi ibu untuk menurunkan intensitas nyeri post operasi, semakin sering ibu melakukan mobilisasi dini maka ibu akan semakin merasakan pengurangan nyeri luka operasinya, hasil penelitian ini dapat disumpulkan bahwa terdapat pengaruh mobilisasi dini terhadap penurunan intensitas nyeri pada pasien post operasi sectio casarea di Rumah Sakit se kota Bengkulu. Disarankan bagi Rumah sakit disarnakan agar dapat melakukan dan menganjurkan pasien untuk melakukan mobilisasi dini, dan melakukan pemantauan apakah pasien benar-benar melakukan mobilisasi dini dan bagi pasien disarankan kepada pasien yang menjalani sectio caesarea untuk segera melakukan mobilisasi dini setelah pasca SC secara bertahap.

\section{UCAPAN TERIMA KASIH}

Peneliti mengucapakan rasa terima kasih yang sebesar-besarnya kepada pihak-pihak yang telah membantu dalam pelaksanaan kegiatan penelitian ini 1) Kemenristekdikti yang telah memberikan dana dalam penelitian ini, 2) Dekan Fakultas Ilmu Kesehata Universitas Dehasen Bengkulu yang telah memberikan izin kepada penelitia untuk melakukan penelitian di antara jam kerja dan telah mengeluarkan surat tugas kepada peneliti, 3) Lembaga Kesbangpol Provinsi Bengkulu yang telah memberikan rekomendasi izin penelitian, 4) Direktur rumah sakit se kota Bengkulu yang telah memberikan izin penelitian, 5) Kepala ruangan Kebidanan rumah sakit se kota Bengkulu yang telah membantu pelaksanaan penelitian.

\section{DAFTAR PUSTAKA}

1. Kasdu, D. Operasi Caesar Masalah dan Solusinya. Jakarta. Puspa Swara; 2010.

2. Dewi, Nia Risa, Siregar, Maimah Rafni. 2014. Faktor-Faktor Yang Berhubungan Dengan Pelaksanaan Ambulasi Dini Pada Ibu Postpartum Dengan Sectio Caesarea Di Ruang Rawat Gabung IRNA Kebidanan dan Penyakit Kandungan RSUP Dr. Moh. Hoesin Palemban; 2007. Jurnal Generic. ISSN 1907-4093, diakses 9 April 2016 dari http://eprints.unsri.ac.id 
3. Kemenkes RI. Rencana Strategis Kementerian Kesehatan RI 2015-2019. Jakarta: Kementerian Kesehatan RI; 2015.

4. Kristiani, D \& Latifah, L. Pengaruh Tehnik Relaksasi Autogenik Terhadap Skala Nyeri Pada Ibu Post Operasi Sectio Caesarea (SC) di RSUD Banyumas, Skripsi, Universitas Soedirman; 2013.

5. Carpenito, L, J.. Diagnosis Keperawatan, Aplikasi Pada Praktek Klinis. Alihbahasa: Kadar, K.S., Evriyani, D., Yudha, E.K., Ester, M,Edisi 9. Jakarta. EGC; 2009.

6. Corwin, E.J. Patofisiologi. Jakarta. EGC ; 2008.

7. Arum R. ubungan Mobilisasi Dini dengan Intensitas ibu post sectio caesarea di RSD Haryoto Lumajang, Jurnal Kesehatan, Universitas Brawijaya Malang; 20011.

8. Astutik, P. Mobilisasi Terhadap Penurunan Tingkat Nyeri Ibu Postoperasi Sectio Caesarea di Care Unit Ruang Post Anesthesia RSUD dr. Harjono Ponogroho; 2014. Jurnal Kesehatan Stikes Satriya Bhakti Nganjuk, Vol. 1, No. 1, Juni 2014

9. Grace C. Pengetahuan, Sikap dan Pelaksanaan Mobilisasi Dini Ibu Pasca Salin dengan Seksio Sesaria.Jurnal Kesehatan. Fakultas Keperawatan Universitas Sumatera Utara; 2012. 